\title{
Nested polymerase chain reaction and in situ hybridization for detection of nucleopolyhedrosis
}

\author{
Chung-Hsiung Wang a, Hsi-Nan Yang ${ }^{\text {, }}$, Hwei-Chung Liu ${ }^{\text {b }}$ \\ Guang-Hsung Kou ${ }^{\text {b }}$, Chu-Fang Lo ${ }^{\text {b,* }}$ \\ a Department of Entomology, National Taiwan University, Taipei 106, Taiwan, ROC \\ ${ }^{\mathrm{b}}$ Department of Zoology, National Taiwan University, Taipei 106, Taiwan, ROC
}

Received 8 June 1999; received in revised form 3 September 1999; accepted 6 September 1999

\begin{abstract}
A nested polymerase chain reaction (PCR) and in situ hybridization were developed for detection of baculoviruses in insects or other arthropods with nucleopolyhedrosis. The nested PCR was based on the sequences of polyhedrin genes from baculoviruses. Two sets of primers were designed, primers set, 35/36, was for the first step of amplification and yielded a product of around $680 \mathrm{bp}$, the second primer, 35-1/36-1, was designed to yield a product of around $335 \mathrm{bp}$ from the fragment amplified by the first primer set. The sensitivity of this two-step amplification was 100 to 1000 times higher than that of the one-step amplification by primer set (35/36). Samples which contained baculovirus DNA yielded an amplification product showing the expected DNA fragment mobility, whereas nucleic acid extracted from tissue samples of clinically healthy insects or uninfected cells showed no such DNA fragment, thereby confirming the specificity of the primers. Using the 35/36 amplicon as a probe, the PenuNPV-infected cells show positive reaction by in situ hybridization. Two-step DNA amplification and in situ hybridization with the DNA probe developed in the present paper provide effective detection and diagnostic tools for screening insects or other arthropods, especially crustacean species, crabs and shrimps, for baculovirus infections, and may be important in preventing (and/or controlling/enhancing) the infection of baculoviruses. (C) 2000 Elsevier Science B.V. All rights reserved.
\end{abstract}

Keywords: Baculovirus; Detection; In situ hybridization; NPV; PCR

\section{Introduction}

The family Baculoviridae is divided two genera: nucleopolyhedrovirus (NPV) and granulovirus (GV). Over 800 different baculovirus isolates have

\footnotetext{
* Corresponding author. Tel./fax: + 886-2-27368179.

E-mail address: gracelow@ccms.ntu.edu.tw (C.-F. Lo)
}

been reported, of which 504 NPVs and 135 GVs are recorded by International Committee on Taxonomy of Virus (ICTV; Murphy et al., 1995). Baculoviruses are significant pathogens of arthropods, especially insects, that can cause a serious and often fatal disease, nucleopolyhedrosis, both in natural populations and laboratory-reared insects. It is characteristic of 
nucleopolyhedrosis for the infected insects to have a large number of occlusion body (OBs) in their hemolymph. The OBs, which are formed in the late phase of infection, protect the viruses from the unfavorable environment outside the host insects (Vlak and Rohrmann, 1985), and this helps to make the baculoviruses attractive biological agents for the control of insect pests. The OBs have a crystalline protein lattice, comprised primarily of polyhedrin. Polyhedrin, with a molecular weight of around $29 \mathrm{kDa}$, accounts for about $95 \%$ of the mass of the OBs (Rohrmann, 1986). Although less than 20 baculoviruses have been studied at the molecular level (Vlak and Rohrmann, 1985; Miller, 1988), the evidence has consistently suggested that the polyhedrin gene of baculoviruses is a highly conserved nonessential gene with high expression towards the end of infective cycle. In a previous paper we reported that lepidopteran NPV polyhedrins are closely related to one another and have $85-99 \%$ amino acid identity (Chou et al., 1996), while van Strien et al. (1992) reported similarities in the range $73-98 \%$. With these characteristics, the baculoviruses have also prove useful as expression vectors and they are now widely used for large-scale production of biological agents (Luckow and Summers, 1988).

In an epizootic in an insect population, persistent infection by a baculovirus may be an important factor in the induction, transmission, and spread of the virus (Burand et al., 1986). Apparently healthy insects collected from the field are, in fact, often infected persistently with a baculovirus, although symptoms are not obvious and indeed not always even detectable. Disease development occurs after a period of rearing in the laboratory and causes subsequently considerable mortality. Persistent infections may also be caused by several defective mutants of baculoviruses, several of which have been isolated (Brown et al., 1985; Fraser, 1986). By producing persistent infections in the insect population, these mutants may also help to ensure the survival of the virus. Persistent infection by baculoviruses or detective baculovirus also creates serious difficulties for laboratories which rear insects for bioassays or experimental infection with other pathogens or even production of heterogeneous proteins. All of these problems could be addressed, however, if a reliable method for detecting baculovirus in insects were to be made available.

The infective cycle of a baculovirus consists of two phases in which two distinct progeny viruses, extracellular viruses (ECVs) and occluded viruses $(\mathrm{OVs})$. Both progeny viruses are different not only in morphology but also in protein content. Furthermore, in vivo and in vitro infective studies of NPVs have shown that most NPVs are replicated effectively only in a limited number of host species. Given that the objective of the present study was to develop a DNA-based detection method for baculoviral infection, all of this argues that an immunological approach would not be appropriate. On the other hand, DNA-based detection with a PCR (polymerase chain reaction) primer set would likely be much more successful provided that a suitable highly conservative fragment from baculoviral genomes could be identified. Polyhedrin and $p 10$ genes, both of which are highly expressed in the later infection cycle were considered, and based on the known sequences of both genes (Chou et al., 1996, 1997; van Oers and Vlak, 1997). Polyhedrin gene was found to be most suitable for our purpose. In a previous paper (Chou et al., 1996), a primer set (35/36) was described for amplifying a polyhedrin gene fragment of around $680 \mathrm{bp}$. In the present study, this amplicon of polyhedrin gene was used as a probe to detect the NPV-infected tissues and cells, and also describe a second primer set (35-1/36-1) which was designed to increase PCR sensitivity. This primer set yielded an amplicon of expected size, around $335 \mathrm{bp}$, and the specificity and sensitivity of this diagnostic nested PCR was evaluated by testing with several different species of NPV. The results indicated that in situ hybridization and the nested PCR assay provided a rapid and efficient method for detecting baculoviral infection. 


\section{Material and methods}

\subsection{Insect}

Specimens of the insect, Perina nuda (Lepidoptera: Lymantriidae), were obtained and reared in the laboratory with leaves of Banyan, Ficus spp. The noctuid pests, Spodoptera litura and $S$. exigua were reared as in previous paper (Shih et al., 1995). Twenty third instar larvae of each species were infected by diet surface treatment with OBs (about $2.5 \times 10^{3} \mathrm{OBs} /$ larvae). The moribund larvae with nucleopolyhedrosis were collected and stored in $-20^{\circ} \mathrm{C}$.

\subsection{Cell lines}

The NTU-PN-HH (Wang et al., 1996) and SL (S. litura) (Shih et al., 1997) cell line were established in our laboratory. Other cell lines, IPLBSF-21AE (S. frugiperda cell line), and IPLB-LD-652Y (Lymantria dispar cell line) were kindly provided by Dr. M.J. Fraser of University of Notre Dame and UCR-SE-1 ( $S$. exigua cell lines) was kindly provided by Dr. W.D. Gelernter of University of California. All cell lines except UCR-SE-1 were grown at $28^{\circ} \mathrm{C}$ in TNM-FH medium (Hink and Strauss, 1976) containing 100 $\mathrm{IU} / \mathrm{ml}$ penicillin, $100 \mu \mathrm{g} / \mathrm{ml}$ streptomycin and 1.25 $\mu \mathrm{g} / \mathrm{ml}$ fungizone, supplemented with $10 \%$ fetal calf serum (FCS) which had been inactivated at $56^{\circ} \mathrm{C}$ for $30 \mathrm{~min}$. UCR-SE-1 cells were grown at the same temperature in a modified TNM-FH medium containing the same antibiotics and supplement at an osmotic pressure of $400 \mathrm{mOsm}$ (Gelernter and Federici, 1986).

\subsection{Viruses}

The five viruses were used in this study: AcMNPV-TWN4 (Autographa califorica NPV Taiwan isolate from $S$. exigua) was propagated in IPLBSF-5-5C (Wang et al., 1992) or SL cell lines (Shih et al., 1997); PenuNPV ( $P$. nuda NPV) and LyxyNPV (Lymantria xylina NPV) were collected from infected larvae (P. nuda and L. xylina) and propagated in their permissive cell lines (NTUPN-HH and IPLB-LD-652Y, respectively) (Wang et al., 1996); SpltNPV and SpeiNPV were obtained from moribund larvae ( $S$. litura and $S$. exigua, respectively).

\subsection{In vitro viral propagation}

In vitro viral propagation of NPVs in cell lines was accomplished by infection of $3 \times 10^{6} \log$ phase cells per $25 \mathrm{~cm}^{2}$ tissue culture flask with the appropriate amount of virus (MOI less than 1). After $1 \mathrm{~h}$ of adsorption, the inoculum was removed and fresh medium was added. The infected cells were incubated at $28^{\circ} \mathrm{C}$ and examined daily for 1 week.

\subsection{OB/virion purification and genomic DNA extraction}

The isolation and purification of OBs and NPVs from insect tissues and cells were carried out as described in a previous paper (Chou et al., 1996). Briefly, the infected tissues and cells were homogenized in $1 \times$ TE buffer $(10 \mathrm{mM}$ Tris- $\mathrm{HCl}$, $1 \mathrm{mM}$ EDTA, pH 7.6) and filtered with a copper net $\left(3.5 \times 10^{3}\right.$ meshes $\left./ \mathrm{cm}^{2}\right)$. The filtrates were centrifuged at $1,000 \times g$ for $20 \mathrm{~min}$ at $4^{\circ} \mathrm{C}$ and the pellets were resuspended with the same buffer. Linear sucrose gradients, $35-65 \%(\mathrm{w} / \mathrm{w})$, were used for purification of OBs at $100000 \times g$ for 30 min at $4^{\circ} \mathrm{C}$. The $\mathrm{OB}$ band was collected and diluted to 3 times its original volume with distilled water and then centrifuged again at $1000 \times g$ for $30 \mathrm{~min}$ at $4^{\circ} \mathrm{C}$. The purified $\mathrm{OBs}$ were digested with DAS (diluted alkaline solution) and the dissolved solution was centrifuged at the same sucrose gradients at $100,000 \times g$ for $60 \mathrm{~min}$ at $4^{\circ} \mathrm{C}$. Five viral bands were collected and diluted with 3 volumes of $0.1 \times$ TE buffer and then precipitated at $100,000 \times g$ for $30 \mathrm{~min}$ at $4^{\circ} \mathrm{C}$. The purified viruses were stored in eppendorf tubes at $4^{\circ} \mathrm{C}$. The genomic DNA of PenuNPV was obtained from the virion by proteinase $\mathrm{K}$ treatment and phenol-chloroform extraction (Lee and Miller, 1978).

The genomic DNAs of the uninfected cells from cell lines (PN and SF cells) were extracted according to the method of Summers and Smith (1987). Briefly, the media of the log-phase cells in $25 \mathrm{~cm}^{2}$ 
tissue culture flasks were removed and $5 \mathrm{ml}$ lysis buffer (0.03 M Tris, $\mathrm{pH} 7.5 ; 0.01 \mathrm{M} \mathrm{Mg}$ Acetate; and $1.0 \%$ Nonidet P-40) was added for $10 \mathrm{~min}$. The cell suspension was transferred to a $15 \mathrm{ml}$ centrifuge tube and kept on ice for $5 \mathrm{~min}$. During this time, the cell suspension was vortexed 4-5 times at full speed for about $15 \mathrm{~s}$ each time. The nuclei were pelleted at $500 \times g$ for $3 \mathrm{~min}$ and the supernatant was discarded. The nuclei were washed in cold $1 \times$ PBS and repelleted. The pelleted nuclei were mixed with $4.5 \mathrm{ml}$ extraction buffer (each litter contains $12.1 \mathrm{~g}$ Tris; $33.6 \mathrm{~g}$ $\mathrm{Na}_{2}$ EDTA. $2 \mathrm{H}_{2} \mathrm{O}$; and $14.9 \mathrm{~g} \mathrm{KCl}, \mathrm{pH} 7.5$ ) and added $200 \mu \mathrm{g}$ proteinase $\mathrm{K}$ and incubated at $50^{\circ} \mathrm{C}$ for $1 \mathrm{~h}$. The $0.5 \mathrm{ml} \mathrm{10 \%} \mathrm{Sarcosyl} \mathrm{was} \mathrm{added} \mathrm{and}$ incubated at $50^{\circ} \mathrm{C}$ for $2 \mathrm{~h}$. The genomic DNAs of cells were obtained from the nuclei by phenolchloroform extraction as described earlier for viral purification.

\subsection{Preparation of $P$. nuda DNA from} hemolymph of laboratory-reared larvae and ovaries of female adult P. nuda

Each $100 \mu$ hemolymph of 14 4th instar laboratory-reared $P$. nuda larvae was collected by puncturing abdominal legs and mixed with $1 \times$ lysis buffer on the ice and processed for the DNA preparation as earlier description. Six laboratoryreared $P$. nuda virgin female adults were dissected and the ovaries were washed in cold $1 \times \mathrm{TE}$

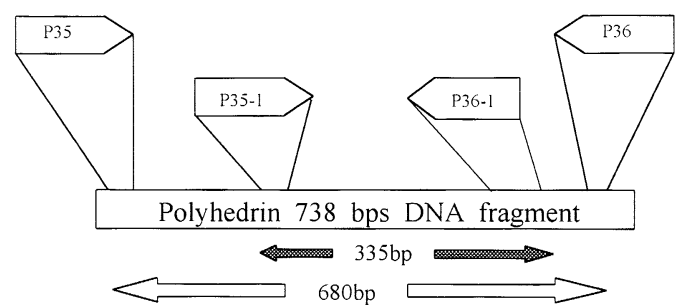

Primer 35

Primer 36

Primer 35-1

5'-ACY TAY GTG TAC GAC AAC AAA TAY TAC AAA-3' 5'-GGY GCG TCK GGY GCA AAY TCY TTW ACY TTR AA-3'

Primer 36-1

5'-CSA TSA AGA RAT GRT GGW CKT YYT CST-3'

5'-CKT SGA GGA GWA YTT CCT CCT CMT CGG-3'

Fig. 1. Diagram of the polyhedrin gene. Location and sequence of the primers used for PCR amplications are indicated. The predicted amplicon of $35 / 36$ primer set with viral DNA temple is $680 \mathrm{bp}$ and $35-1 / 36-1$ primer set is $335 \mathrm{bp}$. buffer twice and homogenized and processed for the DNA preparation. The DNAs extracted from larvae and ovaries were detected by one-step and nested PCR detection for NPV infection.

\subsection{PCR amplification of viral DNA polyhedrin gene}

The nested primer sets for the PCR derived from the highly conserved regions of published polyhedrin gene sequences. For one-step diagnostic PCR, the primer sequences of primer 35, 5'ACY TAY GTG TAC GAC AAC AAA TAY TAC AAA-3' and primer 36, 5'-GGY GCG TCK GGY GCA AAY TCY TTW ACY TTR AA-3' were the same as those reported in a previous paper (Chou et al., 1996). For the nested diagnostic PCR, another primer set, 35-1/36-1, was designed. The consisted of primer 35-1, 5'-CSA TSA AGA RAT GRT GGW CKT YYT CST-3', and 36-1, 5'-CKT SGA GGA GWA YTT CCT CCT CMT CGG-3', where $\mathrm{Y}$ represents $\mathrm{T}$ or $\mathrm{C}, \mathrm{R}$ represents $A$ or $G, K$ represents $T$ or $G, W$ represents $\mathrm{A}$ or $\mathrm{T}, \mathrm{S}$ represents $\mathrm{G}$ or $\mathrm{C}, \mathrm{M}$ represents A or C. PCR was performed in a $100 \mu \mathrm{l}$ reaction mixture containing 2.5 unit Taq polymerase (Promega), $100 \mathrm{ng}$ of viral DNA, $0.5 \mu \mathrm{g}$ of each primer, $200 \mu \mathrm{M}$ of four dNTP and $1 \times$ reaction buffer (10 mM Tris- $\mathrm{HCl}, \mathrm{pH} 9.0,50 \mathrm{mM}$ $\mathrm{KCl}, 1.5 \mathrm{mM} \mathrm{MgCl}_{2}, 0.1 \%$ Triton-100). Thirty amplification cycles were carried out in a MJR PTC-100 Thermocycler (Watertown, MA, USA) with each cycle consisting of 3 steps: denaturing at $94^{\circ} \mathrm{C}$ for $1 \mathrm{~min}$, followed by annealing at $50^{\circ} \mathrm{C}$ for $1 \mathrm{~min}$, and elongating at $72^{\circ} \mathrm{C}$ for $3 \mathrm{~min}$. There was a final extension step of $5 \mathrm{~min}$ at $72^{\circ} \mathrm{C}$. PCR products were analyzed in $1.5 \%$ agarose gels in TAE buffer (40 mM Tris-acetate, $1 \mathrm{mM}$ EDTA, $\mathrm{pH} 8.0$ ) containing $0.5 \mu \mathrm{g} / \mathrm{ml}$ ethidium bromide, and then visualized with short-wave ultraviolet light. For the nested amplification, $100 \mathrm{ng}$ of the first step PCR product in a new reaction tube was used as the DNA template and the reaction mixture was the same as in the first step. The anticipated sizes of the 35/36 and 35-1/36-1 PCR products were approximately $680 \mathrm{bp}$ and $335 \mathrm{bp}$ respectively (Fig. 1). 
A

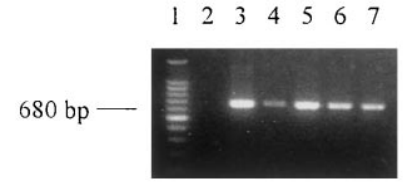

B

$\begin{array}{lllllll}1 & 2 & 3 & 4 & 5 & 6 & 7\end{array}$

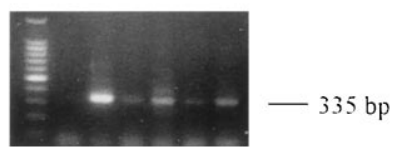

Fig. 2. The fragments of PCR-amplified polyhedrin genes by the primer sets of 35/36 (A) and 35-1/36-1 (B), the amplicons were coincident with the predicted sizes of $680 \mathrm{bp}$ and $335 \mathrm{bp}$ respectively, whereas the host DNA (Perina nuda DNA) was negative. Lane 1: 100 bp DNA ladder; Lane 2: P. nuda DNA; Lane 3-7: AcMNPV; SpeiNPV; SptlNPV; PenuNPV; and LyxyNPV DNAs respevtively.

\subsection{One-step and nested PCR detection}

The template DNAs from cells, OBs, ECVs, hemolymph, and ovaries of female adults of $P$. nuda were used for one-step and nested PCR detection. The cell and OB DNAs, about $100 \mathrm{ng}$, were tested for specificity of the reactions. Ten fold serial dilutions of DNAs from $1 \times 10^{8} \mathrm{OBs} /$ $\mathrm{ml}$ of PenuNPV, SpeiNPV, AcMNPV and SpltNPV or $3 \times 10^{8} \mathrm{PFU} / \mathrm{ml}$ of PenuNPV ECV were tested for sensitivity of the reaction. $200 \mu \mathrm{l}$ DNAs $\left(1 \times 10^{6} \mathrm{OBs} /\right.$ well $)$ were used for each detection. The DNAs extracted from the hemolymph of 4 th instar laboratory-reared $P$. nuda larvae and ovaries of virgin female adults were examined for availability of the reaction. The PCR was assessed based on the presence or absence of the predicted amplicons in agarose electrophoresis.

\subsection{In situ hybridization}

The infected $P$. nuda larvae with PenuNPV were sampled and then fixed in Davidson's AFA fixative $33.0 \%$ of $95 \%$ ethyl alcohol, $22.0 \%$ of $100 \%$ formalin, $11.5 \%$ glacial acetic acid, and $33.5 \%$ of distilled water; Lightner, 1996). The fixed tissues were dehydrated, embedded in paraffin and sectioned at approximately $6 \mu \mathrm{m}$ thickness on a rotary microtome. The tissue sections were deparaffinized in xylene and rehydrated by a serial graded alcohol (absolute to 50\%) and finally with distilled water. The sections were treated with $2 \mathrm{~N} \mathrm{HCl}$ for $5 \mathrm{~min}$, then washed twice for $1 \mathrm{~min}$ with distilled water. The slides were treated for $30 \mathrm{~min}$ with $100 \mu \mathrm{g} / \mathrm{ml}$ proteinase $\mathrm{K}$ at $37^{\circ} \mathrm{C}$. After the proteolytis treatment, postfixation was carried out by cold $0.4 \%$ formaldehyde. The hybridization and coloration procedures were as described by Lightner (1996). The 680 bp DNA fragment of the $35 / 36$ PCR products was used for the preparation of the DNA probe. The product was gel purified and nonradioactively labeled with digoxigenin-dUTP using a random priming method available from Boehringer Mannheim Biochemical, Bedford, England. After coloration, the cells were counterstained with $0.5 \%$ bismarck brown for $1 \mathrm{~min}$ and then followed by dehydration. The sections were mounted with Entellan mounting medium (Merck Corporation). Microphotographs were taken under an Olympus Research Microscope Model AHBT3.

For in vitro study, the PN cells were cultured on coverglasses and inoculated with PenuNPV (MOI less than 1) at $36 \mathrm{~h}$ post-inoculation. The infected PN cells were then fixed in Davidson's AFA fixative. The cells were washed with distilled water. The protocols followed for in situ hybridization with the $680 \mathrm{bp}$ DNA probe were the same as described above.

\section{Results}

\subsection{Amplification of polyhedrin gene fragment from DNAs extract from purified viruses and insect cells}

Fig. 2 shows P. nuda DNA (lane 2) and baculoviral DNAs prepared from different viruses, AcMNPV; SpeiNPV; SptlNPV; PenuNPV; and LyxyNPV (lanes 3-7 respectively) using primer set $35 / 36$ or $35-1 / 36-1$. The size of the amplicons 


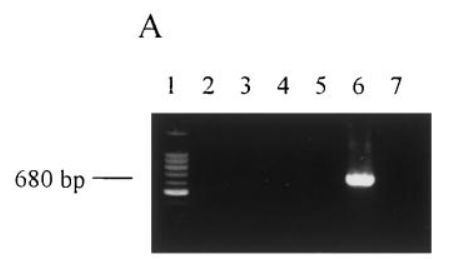

B



Fig. 3. PCR-amplified polyhedrin-gene fragments by the primer sets of 35/36 (A) and 35-1/36-1 (B) from DNAs of cell lines which are routinely maintained in our laboratory with the positive control of PenuNPV DNA. Lane 1: 100 bp DNA ladder; Lane 2-5: DNAs from IPLB-SF-21AE; NTU-PN-HH; UCR-SE-1; and NTU-SL 7B cells respevtively; Lane 6: PenuNPV DNA; Lane 7: buffer.

found in each tested NPV DNA coincided with the predicted sizes of 680 bp (Fig. 2A) and 335 bp (Fig. 2B) respectively, whereas the host DNA (P. nuda DNA) (Fig. 2A and B, Lane 2) and the DNAs extracted from the cells that are routinely maintained in our laboratory (Fig. 3) were negative in both reactions. Fig. 3B shows the nested PCR reaction with both primer sets, and the two predicted bands (680 and $355 \mathrm{bp}$ ) are both present in the positive control of PenuNPV DNA (Lane 6). These results demonstrated the universality of these primer sets for the tested NPV DNAs and confirmed the specificity of both the one-step and nested PCR with these primer sets to NPV DNAs.

\subsection{Comparison of sensitivity of one-step and nested PCR amplification}

Fig. 4 shows the results for the 10 fold serial dilutions of the DNAs extracted from OBs with the 35/36 primer set. Detectable dilutions of PenuNPV (A), SpeiNPV (B), AcMNPV (C), and SpltNPV (D) were as low as $10^{-5}, 10^{-5}, 10^{-6}$, and $10^{-6}$ respectively, which implies that the sensitivity of the one step reaction can be up to less than $100 \mathrm{OBs} /$ well, which corresponds to about $0.57 \mathrm{ng}$ of viral DNA.

In the corresponding results for the nested PCR amplification with the primer set $35 / 36$ and $35-1 / 36-1$, the sensitivity was $100 \times(\mathrm{A} \& \mathrm{~B})$ to $1000 \times(C \& D)$ higher than one-step amplification (Fig. 5).
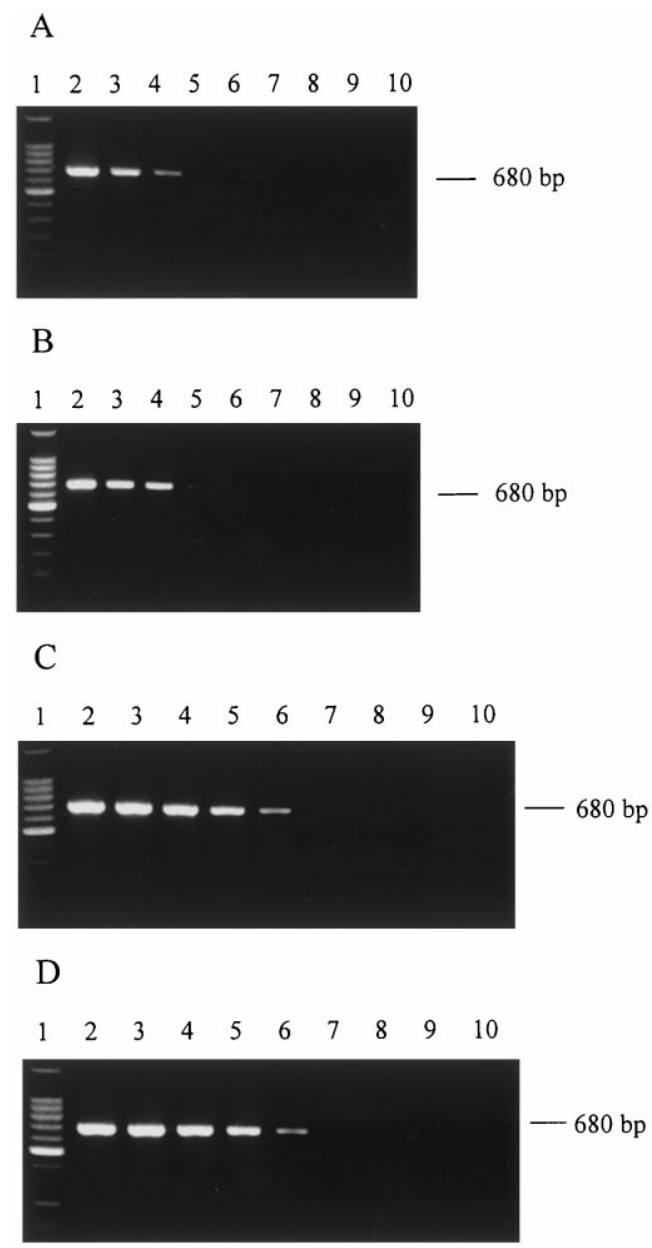

Fig. 4. PCR-amplified detection of baculoviruses by the primer set 35/36 from OB-extracted DNAs with ten-fold serial dilution of initial concentration of $1 \times 10^{6} \mathrm{OBs} /$ well. A: PenuNPV DNA; B: SpeiNPV DNA; C: AcMNPV DNA; and D: SpltNPV DNA. 
A

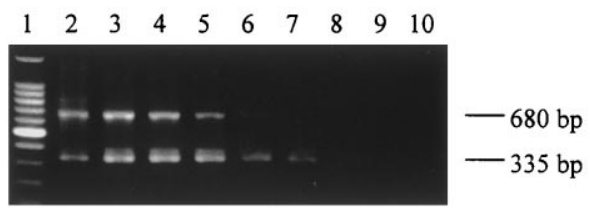

B

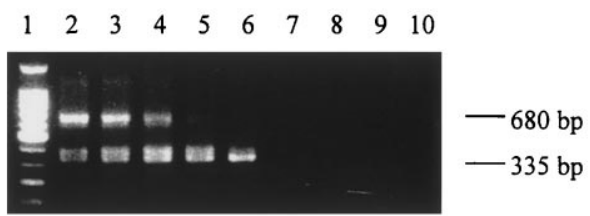

C



D

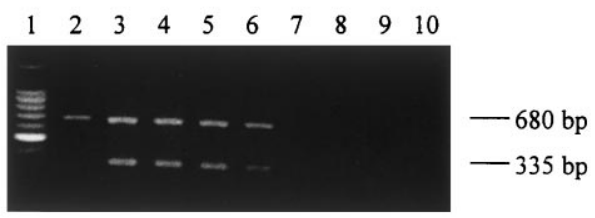

Fig. 5. Nested PCR-amplified detection of baculoviruses by the primer sets of $35 / 36$ and 35-1/36-1 from OB-extracted DNA with ten-fold serial dilution of initial concentration of $1 \times 10^{6} \mathrm{OBs} /$ well. A: PenuNPV DNA; B: SpeiNPV DNA; C: AcMNPV DNA; and D: SpltNPV DNA.

3.3. Amplification of polyhedrin gene fragments from PenuNPV DNA extracted from extracellular virus $(E C V)$

PenuNPV DNAs extracted from ECV and subjected to 10 fold serial dilution were also examined by one-step and nested PCR detection. The sensitivities of one-step and nested PCR were less than $3 \times 10^{3}$ PFUs/well (Fig. 6A) and $3 \times 10^{1}$ PFUs/well (Fig. 6B), respectively. Here also the sensitivity of nested PCR amplification was 100 fold higher than one-step amplification.

\subsection{Amplification of polyhedrin gene fragment}

from DNAs extracted from hemolymph of infected larvae and ovary of adult female Perina nuda

Fig. 7 shows the PCR-amplified detection of PenuNPV infection by one-step (Fig. 7A) and two-step (Fig. 7B) amplification from DNAs extracted from the hemolymph of fourteen laboratory-reared $P$. nuda larvae (Lane 2-15) with the positive control of PenuNPV (Lane 16) and the negative control of buffer (Lane 17). All the samples showed a negative reaction in one-step detection, whereas, with one exception (Fig. 7B: Lane 11), all the samples were positive in two-step detection. These results showed the presence of a persistent PenuNPV infection in the laboratoryreared $P$. nuda larvae. In fact, the rest of the stock from which the tested larvae were taken all died from PenuNPV infection after 1-2 weeks.

Fig. 8 shows the PCR-amplified detection of PenuNPV infection by one-step (Fig. 8A) and two-step (Fig. 8B) amplification from DNAs ex-

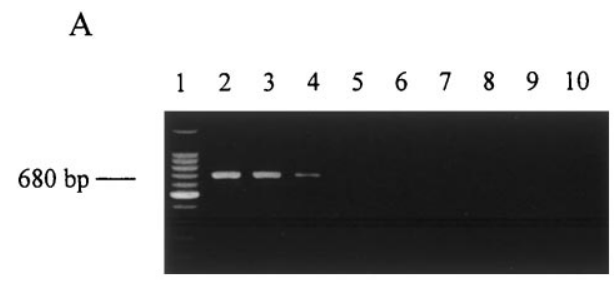

B

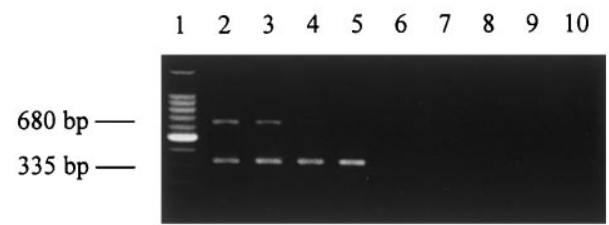

Fig. 6. PCR detection of baculoviruses by one-step, 35/36 primer set (A) and two-step 35/36 and 35-1/36-1 primer sets (B) amplifications from PenuNPV DNAs extracted from ECV as template with ten-fold serial dilution of initial concentration of $3 \times 10^{6} \mathrm{PFUs} /$ well. 
A $\begin{array}{lllllllllllllllll}1 & 2 & 3 & 4 & 5 & 6 & 7 & 8 & 9 & 10 & 11 & 12 & 13 & 14 & 15 & 16 & 17\end{array}$

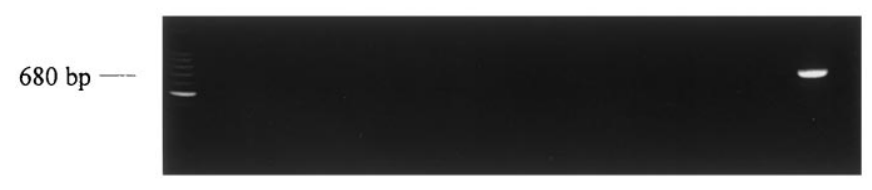

B $\begin{array}{lllllllllllllllll}1 & 2 & 3 & 4 & 5 & 6 & 7 & 8 & 9 & 10 & 11 & 12 & 13 & 14 & 15 & 16 & 17\end{array}$

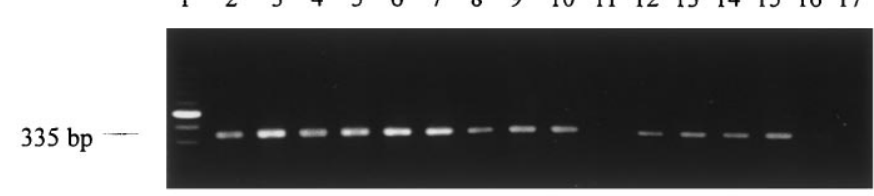

Fig. 7. PCR-amplified detection of PenuNPV infection by one-step (A) and two-step (B) amplifications from DNAs extracted from the hemolymph of laboratory-reared P. nuda larvae with the positive control of PenuNPV DNA (Lane 16) and the negative control of buffer (Lane 17).

tracted from laboratory-reared $P$. nuda female adults' ovaries with the positive control of PenuNPV (Lane 7) and the negative control of buffer (Lane 8). Except for one very weak positive result in two-step detection that might have come from contamination of the ovary during its excision (Fig. 8B: lane 4), all the other samples were negative in both one-step and two-step detection. This result implies that the transovum or transovarial transmission of PenuNPV is probably not a major route of transmission for this virus.

\subsection{Detection of PenuNPV infected organs in the} Perina nuda larvae and PenuNPV infected PN cells in vitro by in situ hybridization

At $96 \mathrm{~h}$ post-inoculation, the mid-gut of $P . n u d a$ was found to be PenuNPV-positive by in situ hybridization (Fig. 9A). The blue precipitate was presented in the nuclei of the columnar epithelial cells and also between the gut cells. Except silk gland, all the other organs showed more or less PenuNPV-positive cells (Table 1). Some cell nuclei were enlarged to more than twice the diameter of a normal nucleus but some cell were lysed. For in vitro study, the infected PN cells had a positive reaction at $36 \mathrm{~h}$ post-inoculation (about $8.5 \%$ ) and the nuclei also seemed to larger than the normal cell (Fig. 9B).

\section{Discussion}

The members of the Baculoviridae are characterized by producing a crystalline protein matrix which has a polyhedral shape for the NPVs and a capsule shape for the GVs. Of the 504 NPVs listed by ICTV, only 15 are recorded species status; for the GVs only 5 out of 135 listed viruses are recognized as species (Murphy et al., 1995). NPVs and GVs both contain a highly conservative gene, known respectively as the polyhedrin and the granulin gene. The nucleotide and amino acid sequences of both genes are over 50\% homologous (Chakerian et al., 1985) and those of interspecies of NPVs are over $73 \%$ homologous

A B

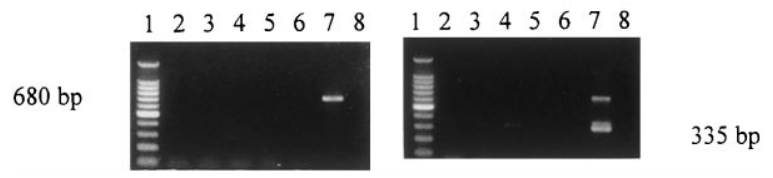

Fig. 8. PCR-amplified detection of PenuNPV infection by one-step (A) and two-step (B) amplifications from DNAs extracted from laboratory-reared $P$. nuda female adults with the positive control of PenuNPV (Lane 7) and the negative control of buffer (Lane 8). Except one is positive in two-step detection (B: Lane 4), the other were negative in both one-step and two-step detection. 
A

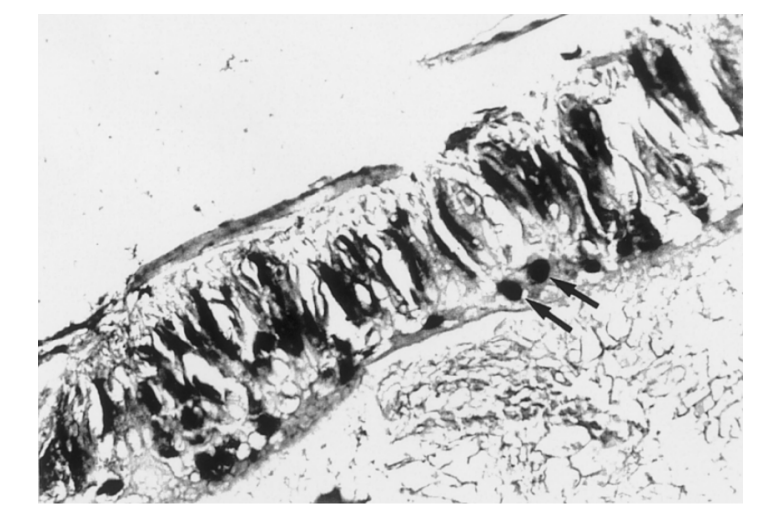

B

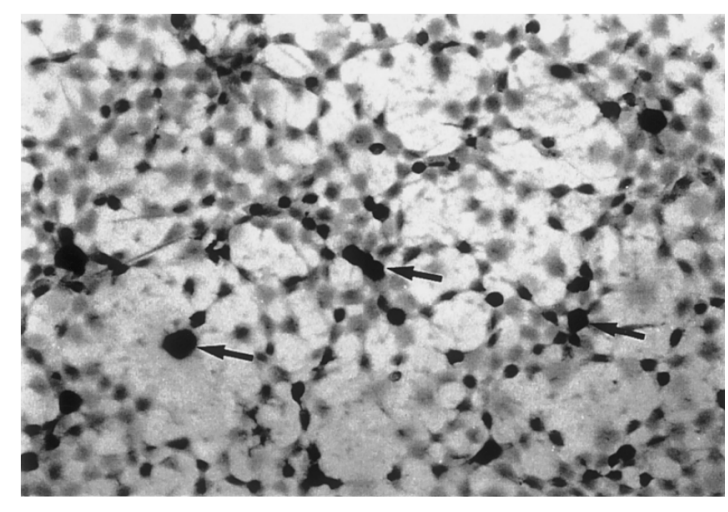

Fig. 9. Detection by in situ hybridization of NPV in (A) the mid-gut of $P$. nuda at $96 \mathrm{~h}$ post-inoculation and (B) the infected PN cells at $36 \mathrm{~h}$ post-inoculation. The infected cells both have positive reactions and the nuclei are hypertrophied (arrows). Scale bar $=50 \mathrm{~nm}$.

(van Strien et al., 1992; Chou et al., 1996). Therefore, antigenic determinants that cross-react exist on viron protein and on the major subunit of polyhedrin and granulin polypeptides (Murphy et al., 1995) and also on the different species polyhedrin or granulin. It is therefore reasonable to use antiserum to polyhedrin or granulin species and DNA as a universal probe to detect baculoviral infection. Two disadvantages of using antiserum to polyhedrin or granulin are inherent however: first, both proteins are produced only in the later phase of the infective cycle and the antiserum fails to react with the viral infection when they are in the early phase of infective cycle, and second, both proteins are deficient and/or present only in very small amounts both in persistent infections and also in infections caused by any of several mutant viruses. In these cases, this immunological detection would be not available. Therefore, DNA-based detection was suggested as the best choice for baculoviral detection.

The DNA-based detection provides a powerful technique of identifying viruses and studying homology between viral nucleic acid. Furthermore the explosive growth of PCR based diagnostics has led to the introduction of many different techniques that allow convenient detection of PCR products, especially nested PCR diagnostic methods. These produce nucleic acid fragments specific to the viruses studied that can be used for characterization and identification. Chou et al., 1996 designed the 35/ 36 primer set from the highly conserved sequences of several reported polyhedrin genes. The AcMNPV polyhedrin fragment, about 680 bp, was amplified as a probe and the PenuNPV polyhedrin gene was successfully cloned. The 35/ 36 primer set was first used to amplify the polyhedrin gene fragment of MBV (Penaeus monodon-type baculovirus) isolated from giant tiger prawn (P. monodon) (Chang et al., 1993), and in the present study, the corresponding

Table 1

The organs of Perina nuda larvae were found to be PenuNPVpositive by in situ hybridization at 96 post-inoculation

\begin{tabular}{ll}
\hline Organ & Infection $^{\mathrm{a}}$ \\
\hline Nerve & + \\
Fatty body & ++ \\
Muscle & ++ \\
Hemolymph & ++ \\
Trachea & +++ \\
Silk gland & - \\
Gut & +++ \\
Malpighian tube & + \\
Gonad & + \\
Epidermal cell & +++ \\
\hline
\end{tabular}

a +++ : Heavy infection, ++ : Moderate infection, + : Light infection, - : No infection. 
fragment was amplified from 5 species of NPV. It is expected that this primer set can be applied to any baculoviruses including granuloviruses.

The second, internal primer set was designed and used successfully to amplify the predicted fragment (335 bp) from the tested NPVs. The sensitivity of this nested amplification was 100-1000 times higher than that of the one-step amplification by the 35/36 primer set. The sensitivity for OB detection varied with the NPV species (Fig. 5). The sensitivity may vary because the number of OVs in each OB may vary with the species and even with the tissues in which the viruses have replicated. For example, as many as $200 \mathrm{OVs}$ per OB have been reported (Ackermann and Smirnoff, 1983) and in partially alkaline-dissolved OBs, 65 PenuNPV OVs were found (unpublished data). Furthermore, the number of nucleocapsids ranges from 1 to as many as 39 nucleocapsids per envelope ( = per OV) in OBs isolated from a larva of the brown-tail moth, Euproctis similis (Kawamoto and Asayama, 1975), 1-8 nucleocapsids per envelope in $P$. nuda and 1-15 nucleocapsids in $S$. litura (unpublished data). Similarly, the amount of baculoviral DNA in each $\mathrm{OB}$ varies with species and also tissue or cell line in which the viruses have replicated. Fig. 6 shows that less than 300 PFU could be detected in our nested PCR detection, which means that the sensitivity to detect AcMNPV OB was over $10^{-10}$ dilution. The most likely reason for this was that AcMNPV OB had a higher virion particle or/baculoviral DNA content than the other examined NPVs.

The results demonstrated that the 680 bp DNA fragment of the 35/36 PCR products can be used as a specific probe to detect PenuNPV in the tissues of infected insects or the infected cells in the PN-HH cell line by in situ hybridization. In situ hybridization techniques have recently been developed for the diagnosis of some other viruses (Bruce et al., 1993; Mari et al., 1993, 1995; Chang et al., 1996). It is more advantageous to use in situ hybridization to detect viral DNA in tissues or cells than to use histological staining or electron microscopy. Because in situ hybridization can accurately provide the precise location of viral DNA present in tissue sections or cells as a result of the highly specific interaction between the probe and the target sequence of viral DNA, they can provide information about the target cell types within a given organ or tissue. Furthermore, it also can detect an occluded baculovirus in the infected tissue before the occlusion body has formed (Chang et al., 1996).

In conclusion, these PCR products can be used not only for detecting baculoviral infection in arthropods by other DNA-based methods (e.g. dot blot hybridization, in situ hybridization, and Southern blot hybridization) but also used to clone the polyhedrin gene from other unknown baculoviruses. With PCR, we have demonstrated that this diagnostic technique for NPV provides an effective tool for detection of persistent NPV infection in insects and other arthropods and also for investigation that are concerned with viral transmission. With in situ hybridization, the viral infection can be detected at an early stage, the degree of infection be determined, and target tissues identified.

\section{Acknowledgements}

This work was supported by the National Science Council under grant No. NSC 88-2311-B-002024-B20.

\section{References}

Ackermann, H.W., Smirnoff, W.A., 1983. A morphological investigation of 23 baculoviruses. J. Invertebr. Pathol. 41, 269-280.

Brown, S.E., Maruniak, J.E., Knudson, D.L., 1985. Baculovirus (MNPV) genomic variants: Characterization of Spodoptera exempta MNPV DNAs and comparison with other Autographa californica MNPV DNAs. J. Gen. Virol. 66, 2431-2441.

Bruce, L.D., Redman, R.M., Lightner, D.V., Bonami, J.R., 1993. Application of gene probes to detect a penaeid shrimp baculovirus in fixed tissue using in situ hybridization. Dis. Aquat. Org. 17, 215-221.

Burand, J.P., Kawanishi, C.Y., Huang, Y.S., 1986. Persistent baculovirus infections. In: Granados, R.R., Federici, B.A. (Eds.), The Biology of Baculoviruses, vol. 1. CRC Press, Boca Raton, Florida, pp. 159-175.

Chakerian, R., Rohrmann, G.F., Nesson, M.H., Leisy, D.J., Beaudreau, G.S., 1985. The nucleotide sequence of the Pieris brassicae granulosis virus granulin gene. J. Gen. Virol. 66, 1263-1269. 
Chang, P.S., Lo, C.F., Kou, G.H., Lu, C.C., Chen, S.N., 1993. Purification and amplification of DNA from Penaeus monodon type baculovirus (MBV). J. Invertebr. Pathol. 62, $116-120$.

Chang, P.S., Lo, C.F., Wang, Y.C., Kou, G.H., 1996. Identification of white spot syndrome associated baculovirus (WSBV) target organs in the shrimp Penuaeus monodon by in situ hybridization. Dis. Aquat. Org. 27, 131-139.

Chou, C.M., Huang, C.H., Lo, C.F., Kou, G.H., Wang, C.H., 1996. Characterization of Perina nuda Nucleopolyhedrovirus (PenuNPV) polyhedrin gene. J. Invertebr. Pathol. 67, 259-266.

Chou, C.M., Huang, C.H., Lo, C.F., Kou, G.H., Wang, C.H., 1997. Molecular cloning and nucleotide sequence of the Perina nuda Nucleopolyhedrovirus (PenuNPV) p10 gene. Zoological Stud. 36 (1), 48-57.

Fraser, M.J., 1986. Ultrastructural observations of virion maturation in Autographa californica nuclear polyhedrosis virus infected Spodoptera frugiperda cell cultures. J. Ultrastruct. Mol. Struct. Res. 95, 189-195.

Gelernter, W.D., Federici, B.A., 1986. Continuous cell line from Spodoptera exigua (Lepidoptera: Noctuidae) that supports replication of nuclear polyhedrosis viruses from Spodoptera exigua and Autographa californica. J. Invertebr. Pathol. 48, 199-207.

Hink, W.F., Strauss, E., 1976. Growth of the Trichoplusia ni (TN-368) cell line in suspension culture. In: Kurstak, E., Maramorosch, K. (Eds.), Invertebrate Tissue Culture, Application in Medicine, Biology, and Agriculture. Academic Press, New York, pp. 297-300.

Kawamoto, F., Asayama, T., 1975. Studies on the arrangement patterns of nucleocapsids within the envelopes of nuclear-polyhedrosis virus in the fat-body cells of the brown tail moth, Euproctis similis. J. Invertebr. Pathol. 26, 47-55.

Lee, H.H., Miller, L.K., 1978. Isolation of genotypic variants of Autographa californica nuclear polyhedrosis virus. J. Virol. 27, 754-767.

Lightner, D.V., 1996. A Handbook of Pathology and Diagnostic Procedures for Diseases of Penaeid Shrimp. World Aquaculture Society, Baton Rouge, Louisiana, USA.

Luckow, V.A., Summers, M.D., 1988. Trends in the development of baculovirus expression vector. Bio/Technology 6, 47-55.

Mari, J., Bonami, J.R., Lightner, D.V., 1993. Partial cloning of the genome of infectious hypodermal and hematopoietic necrosis virus, an unusual parvovirus pathogenic for penaeid shrimps; diagnosis of the disease using a specific probe. J. Gen. Virol. 74, 2637-2643.

Mari, J., Lightner, D.V., Poulos, B.T., Bonami, J.R., 1995. Partial cloning of the genome of an unusual shrimp parvovirus (HPV): use of gene probes in disease diagnosis. Dis. Aquat. Org. 22, 129-134.

Miller, L.K., 1988. Baculoviruses as gene expression vectors. Annu. Rev. Microbiol. 42, 177-199.

Murphy, F.A., Fauquet, C.M., Bishop, D.H.L., Ghabrial, S.A., Jarvis, A.W., Martelli, G.P., Mayo, M.A., Summers, M.D., 1995. Virus Taxonomy, Classification and Nomenclature of Viruses: Sixth Report of the International Committee on Taxonomy of Virus. Arch. Virol. Suppl. 10., Springer-Verlag, pp. 104-113.

Rohrmann, G.E., 1986. Polyhedrin structure. J. Gen. Virol. 67, 1499-1514.

Shih, C.J., Farn, S.S., Wang, C.H., 1995. Characterization of Spodoptera litura nuclear polyhedrosis viruses isolated from Taiwan. Plant Prot. Bull. 37, 157-167.

Shih, C.J., Lin, R.W., Wang, C.H., 1997. Establishment of a cell line from Spodoptera litura (Lepidoptera: Noctuidae) and replication of $S$. litura nuclear polyhedrosis virus in vitro. J. Invertebr. Pathol. 69, 1-6.

Summers, M.D., Smith, G.E., 1987. A manual of Methods for Baculovirus Vectors and Insect Cell Culture Procedures. Texas Agric. Exp. Stn. Bull. No. 1555.

van Oers, M.M., Vlak, J.M., 1997. The baculovirus 10-kDa protein. J. Invertebr. Pathol. 70, 1-17.

van Strien, E.A., Zuidema, D., Goldbach, R.W., Vlak, J.M., 1992. Nucleotide sequence and transcription analysis of the polyhedrin gene of Spodoptera exigua nuclear polyhedrosis virus. J. Gen. Virol. 73, 2813-2821.

Vlak, J.M., Rohrmann, G.F., 1985. The nature of polyhedrin. In: Maramorosch, L., Sherman, K.E. (Eds.), Viral Insecticides of Biological Control. Academic Press, New York, pp. $489-542$.

Wang, C.H., Hung, H.W., Kou, G.H., Lo, C.F., 1992. The characterization of clonal cell strains derived from established IPLB-SF 21AE insect cell line. Acta Zoologica Taiwanica 3 (1), 35-46.

Wang, C.H., Chou, C.M., Liu, H.C., Kau, S.L., Kou, G.H., Lo, C.F., 1996. Continuous cell line from pupal ovary of Perina nuda (Lepidoptera: Lymantriidae) that is permissive to nuclear polyhedrosis virus from $P$. nuda. J. Invertebr. Pathol. 67, 199-204. 